\title{
An interactive web tool as a social innovation that ensures greater efficiency in the realization of the rights of people with disabilities to barrier-free access
}

\author{
Richard Sendi*, Boštjan Kerbler \\ Urban Planning Institute of the Republic of Slovenia, Ljubljana, Slovenia \\ Email address: \\ richard.sendi@uirs.si (R. Sendi), bostjan.kerbler@uirs.si (B. Kerbler)
}

\section{To cite this article:}

Richard Sendi, Boštjan Kerbler. An Interactive Web Tool as a Social Innovation that Ensures Greater Efficiency in the Realization of the Rights of People with Disabilities to Barrier-free Access. Social Sciences. Vol. 2, No. 4, 2013, pp. 142-153.

doi: $10.11648 /$ j.ss.20130204.11

\begin{abstract}
Guaranteeing people with disabilities full access to all aspects of life has, for decades, been accepted as a major global commitment. Notwithstanding the innumerable declarations and supporting legislation that have been adopted to this end, research and daily experiences show that people with disabilities continue to be inhibited, by various barriers, from fully participating in society. The recognition of this state of affairs prompted our search for a new solution that would facilitate greater efficiency in the realization of the rights of people with disabilities to barrier-free access. Such a solution is the interactive web tool we present in this paper. Created as the final result of a three-year research, the web tool is an instrument that enables the execution of concrete actions to remove concrete barriers, with the participation of the general public. On the basis of a review of the relevant literature, we also argue in the paper and provide supportive evidence, that the interactive web tool we developed is a 'social innovation'. We conclude the article with the conviction that the creation of the interactive web tool is a giant step towards the gradual removal of barriers and eventual full inclusion into society of people with disabilities.
\end{abstract}

Keywords: People with Disabilities, Built-Environment Barriers, Communication Barriers, Barrier Free Access, Social Innovation, Interactive Web Tool

\section{Introduction}

According to the World Health Organization's estimate (2011), people with physical disabilities account for one billion of the total world population. These statistical estimates relate, in the majority of cases, to working age population groups. At the European level, it is estimated that functionally impaired people make up $15-20 \%$ of the working age population. This means that one in five to six persons of the working age population (aged 16-64) has either a long-standing health problem or a disability. Given the rapidly increasing populations of older people in developed countries, especially those above 80 years of age, the percentage of functionally impaired people might be expected to grow in the future. In spite of these relatively large numbers, people with disabilities, regrettably, often face discrimination and negative attitudes, and experience various forms of barriers that affect their health, well being and quality of life. The gravity of the problem is elaborately expressed by Gore and Parckar (2010: 3):

"Enjoying equal access to goods and services must be seen as a basic right - it cannot be acceptable for people with disabilities to be denied access to services simply because of their impairment. It is the barriers and inaccessibility that people face that disables them - it is what denies people opportunities, it is what leads to inequality, social exclusion and disability poverty. Whilst access to goods and services is only part of this wider issue, it should be considered a critical aspect of any drive to challenge poverty and to reach a fairer, more equitable society."

'Access', therefore, is not only about transport. It encompasses a broad range of areas such as housing, employment and training, the justice system and leisure services, and especially the built environment and access to information. The realization of the rights of people with disabilities to barrier-free access and facilitation of their active participation in society therefore presents a major challenge worldwide. Due to a growing awareness about these issues, it may be observed that there has been a 
noticeable increase in the number of researchers and other experts engaged in the field. The scholarly literature includes various sub-topics related to this theme. Some authors deal with the problems related to the planning and designing of the built environment (for example Bulos and Teymur, 1993; Balchin and Rhoden, 1998; Imrie 2000; McGrail et al., 2001; Burns, 2004; Harrison, 2004; Imrie, 2004a; Thomas, 2004; Prideaux, 2006; Ellison and Burrows, 2007; Botchwey et al., 2009; Prideaux and Roulstone, 2009; Hutch et al., 2011; Sherman and Sherman, 2012). Irrespective of their various approaches, the general argument put forward by these authors is that the planning and designing of the built environment must always take into account the regulations and standards prescribed for guaranteeing barrier-free access for the disabled. Other authors stress the notion of 'inclusive design' or 'design for all' (for example Coleman, 1997; Hanson, 2004; Goodall and Pottinger, 2010), also referred to as 'universal design' (for example Mace, 1998; Sandhu et al., 2001; Chan et al., 2009; Gosset et al., 2009; Imrie, 2011; Lombardi and Murray, 2011). The so-called 'life-time homes' (for example Brewerton and Darton, 1997; Barlow and Venables, 2004; Milner and Madigan, 2004; Hemingway, 2011) are concrete examples of such design concepts. A lot of attention has also been paid to technological and technical innovations such as 'assistive technologies', 'smart homes', 'telecare' etc. (for example Cowan et al., 1999; Brenton, 2001; Fisk 2001; Hanson 2001; Kelly, 2001; Peace and Holland, 2001; Drewsbury et al., 2004; Heywood, 2004; Imrie, 2004b; Pecora and Cesta, 2007; Pillan and Costa, 2009; Harris, 2010). Such solutions specifically aim at overcoming barriers in the domestic built environment, especially communication barriers, which hinder people with disabilities from performing usual daily routines.

Disability has, for some time now, been recognized also as an important political issue, especially in connection with the guaranteeing of universal human rights. Laws and regulations have been adopted providing for the elimination of all forms of discrimination and the removal of various barriers and restrictions in the environment. At the international level, the year 1993 may be considered as one of the major milestones in this area. This is the year when the UN General Assembly adopted, for the first time, Standard regulations for equal opportunities for the disabled. The other important milestone was the year 2001 when the UN General Assembly recommended the preparation of a Convention on the rights of the disabled. This historical document, which was adopted by the General Assembly in 2006, presents the first legally binding international document concerning disability. Its fundamental aim is to guarantee the realization of human rights and the principle of equal opportunities and equal treatment as well as the prevention of discrimination against the disabled. The Convention recognizes the importance of accessibility to the physical, social and economic environment and access to information and communication technologies in enabling people with disabilities to fully exploit and enjoy human rights and basic freedoms. Within the European Union, the Treaty of Amsterdam stands out as one of the most important documents concerning the disabled. With this document (Article 13), the European Commission adopted the human-rights-based approach as the basic principle for tackling and solving the problems of people with disabilities. The Treaty commits Member States to the long-term implementation of strategies for combating discrimination, promoting social integration and active participation, enhancing education, training, lifelong learning and employment opportunities, facilitating independent living and increasing availability and equality of care and assistive technologies (see EC, 1997). For the implementation of this strategy the European Commission adopted a directive that prescribes the establishment of a common framework for equal treatment in employment and professional qualifications and prohibits any form of discrimination. This legally binding document explicitly forbids discrimination due to invalidity (see EC, 2000). Building on the momentum created and the results achieved in 2003 by the European Year of People with Disabilities, the European Commission introduced a multiannual action plan through to 2010, aimed at mainstreaming disability issues in the relevant Community policies and implementing specific measures in key areas with a view to enhancing the economic and social integration of people with disabilities. One of the issues of the strategy dealt with the designing and construction of buildings in compliance with the principle of universal design aiming to ensure that people with disabilities are guaranteed better and effective access to the built environment and to improve participation in the work place and integration into the economy and society (see EC, 2003). The new European Disability Strategy 2010-2020, launched by the European Commission in November 2010, focuses on accessibility. "To fully participate in our society and economy, people with disabilities need to have easier access to public buildings, public transport and to digital services," stated Viviane Reding, the European Commission's vice-president in charge of justice, fundamental rights and citizenship. According to the strategy, the Commission planned to consider proposing a European Accessibility Act in 2012. The new law would, essentially, set out a general accessibility framework in relation to goods, services and public infrastructure using different instruments such as standardization, public procurement or state aid rules, as well as new technologies, such as assistive devices (see EC, 2010).

However, the adoption of laws, formulation of strategic documents and ratification of international conventions, alone, do not necessarily guarantee their actual implementation in practice. This was precisely one of the major findings of the research conducted within the 6th Framework program entitled Free movements and equal opportunities for all (acronym: LivingAll) which included eleven partners from seven European countries (Austria, Belgium, Italy, Norway, Slovenia (both authors of this article participated), Spain and Great Britain) (see Garcés et 
al., 2007). The results of the research showed that adopted laws are inefficiently or poorly implemented and that in the majority of countries covered by the survey, their implementation is either inadequately, or not at all, monitored. The formal commitment by countries to realize the rights of people with disabilities to barrier-free access is only the first step. This must then be followed by the effective implementation of the commitments undertaken. As such, one of the key recommendations that emerged from the research findings was the need to develop and propose methodologies and mechanisms that would enable policy-makers greater efficiency in the implementation of policies for guaranteeing people with disabilities barrier free-access to all spheres of life.

The urgency to achieve this objective prompted us to conduct a new and more focused research on the situation in Slovenia. The main aim of the research was to carry out a detailed investigation into the main built-environment and communication barriers experienced by people with disabilities in their daily lives and, on the basis of these findings, devise efficient mechanisms for their removal. The research was conducted between 2008-2011 by the Urban Planning Institute of the Republic of Slovenia, in collaboration with the Institute for Social Protection of the Republic of Slovenia (see Sendi et al., 2011). The framework for research was presented by two principle government documents, i.e., Strategija Dostopna Slovenija (Strategy Accessible Slovenia) and the Akcijski program za invalide 2007-2013 (Action Program for people with disabilities 2007-2013). The Strategy is premised on the recognition that care for people with disabilities is one of the most sensitive and most specific aspects of societal and economic development in general. The Strategy sets out the following major objectives: the removal of built-environment and communication barriers; facilitating access to employment, knowledge and information; creating conditions that guarantee equal life opportunities for all functionally impaired persons and the provision of technical support for those that require such support for their successful inclusion in society. These aims are further concretized in the above mentioned Action Program, detailing the goals which must be achieved in individual areas as well as the institutions (governmental and non-governmental) responsible for their realization.

The most important result of the three-year long research was the creation of the interactive web tool which we present in this paper. The interactive web tool, with its main constituent parts, is a novel solution in this area. It enables the efficient detection of existing built-environment and communication barriers and also provides mechanisms for the prevention of the occurrence of new ones. We also argue that the interactive web tool we created is a social innovation. As defined by Hubert et al. (2010: 33), social innovations are "... new ideas (products, services and models) that simultaneously meet the social needs (more effectively than alternatives) and create new social relationships or collaborations. In other words, they are innovations that are not only good for society but also enhance society's capacity to act."

Following the introduction, we first of all present a brief summary of the above mentioned Slovenian research which set the background for developing the interactive web tool. This is followed by the presentation of the web tool's major components and a description of its operation. In the second part of the paper we present a review of the relevant literature, which provides the basis for establishing, in the conclusion, that the interactive web tool is, indeed, a social innovation.

\section{Research Methodology}

The research consisted of three main phases. The first phase involved an extensive survey conducted among people with disabilities and the various organizations for the disabled. The second phase focused on drawing up an inventory of built-environment and communication barriers in public facilities. In the last phase, we concentrated on the development of an efficient solution to the problems addressed, which was the main goal of the research project.

The survey among people with disabilities and the organizations for the disabled was conducted with the help of two questionnaires, one for the individual persons with disabilities and another for the major (larger) disabled people's organizations. The purpose of the survey was to investigate in detail the built-environment and communication barriers, which people with disabilities encounter in their daily lives. The investigation of barriers covered the following areas: health and social care, education, employment, public services, transport, culture and recreation.

The field investigation that was conducted in the second phase aimed at identifying existing barriers in facilities that are meant for public use, i.e., facilities that provide public services (such as hospitals, schools, hotels, etc.) or are used for public functions (such as theatres, sport auditoria, recreation facilities etc.). Guaranteeing full accessibility to all public facilities is one of the major goals of the Strategy Accessible Slovenia. It is, of course, understandable that we could not examine the accessibility of all such facilities in the country during the course of the research project. As such, our approach was to investigate two important public facilities in each one of the major towns of the twelve distinctive regions of Slovenia. The selection of the facilities to examine was based on two principles. First, it was decided that we examine the municipal administration building in each one of the twelve regional major towns. The local administration facility was thus set as a constant. The selection of the local administration facility as a constant was based on the conviction that this is a place that every individual is likely to visit at least once in their life time (registration of residence, obtaining personal documents, regulation of property rights etc.). The examination of the same facility throughout the entire field survey would also enable us to make a comparative analysis of the various 
levels of accessibility of that particular facility in the twelve regional centres. The aim of the comparison was to explore the eventuality of good practices. Having fixed the local administration facility as a constant, the selection of the second facility to be examined in each centre was then based on the requirement that we cover each one of the various spheres of life investigated by the research (health and social care, education, employment, public services, transport, culture and recreation).

In the field survey, we examined the accessibility of facilities for three types of disability, i.e., people with impaired mobility, the blind and partially sighted and the deaf and hard of hearing. In order to ensure the most accurate assessment of accessibility of facilities, we requested for and received help from persons with disabilities. As such, members of the Association of Disabled Students of Slovenia actively participated in the field investigations. We specifically ensured that the persons with disabilities that participated in the field survey included representatives of all the three categories of disability identified above. With these basics in place, we needed to have available an efficient instrument for establishing the actual accessibility or non-accessibility of the facilities examined. For this purpose, we designed a very elaborate technical tool which we termed the inspection list. The inspection list was designed on the basis of a preliminary detailed review of current legislation and all relevant regulations and standards concerning barrier-free access in Slovenia. The inspection list was prepared in such a way that it covered all aspects of accessibility, starting from the exterior space (parking, approach paths leading to the entrance, gradients etc.), followed by the entrance to the building (gate, vestibule) and then the interior of the building (entrance hall/reception/foyer/lobby, stairs/lift, offices meant for public access, public toilets inside the facility etc). The assessment of accessibility also included details such as: door width, floor coverings, height of door knobs, public notice lettering, colouring, lighting, sound systems, tactile markings, induction coils/loops etc. The information gathered was recorded on the inspection list and later entered into a specially designed computer data processing system.

The data collected in the second phase presented the basis for designing the interactive web tool in the third and last phase of the research project. For this purpose, an internet web site was created where the interactive web tool is accessible to the general public.

Starting with a brief summary of the main research findings, we proceed with the presentation of the interactive web tool, followed by a review of the literature on social innovations, which provides the theoretical basis for defining the interactive web tool we created is a social innovation.

\section{Designing the Interactive Web Tool}

The empirical survey conducted in the first phase of the research gave two important findings. First, people with disabilities listed numerous built environment and communication barriers that they continue to experience daily in all the spheres of life, covered by the survey. Almost all the barriers listed ought to have been already removed had the various commitments and adopted legislation been effectively implemented. To this effect, the majority of respondents pointed out noncompliance with regulations and building standards as one of the greatest evils that hinder the achievement of barrier-free environments. In addition to these findings, a high percentage of the respondents made a very important suggestion regarding where to start all efforts aimed at the efficient removal of existing barriers. They suggested conducting a though examination of all facilities intended for public access, with the aim of taking an inventory of all existing built-environment and communication barriers. The idea behind this suggestion was that the registration of barriers would provide a data base which the competent authority (the national building inspectorate) would use to take appropriate measures for their removal. The research team found this proposal exceptionally sensible and readily adopted it for implementation in the second phase of the research project.

The examination of existing built-environment and communication barriers we conducted in phase two, only confirmed the general findings of the first phase of the research. None of the facilities examined was fully accessible. It was also found that facilities are generally most inaccessible to people with sensory impairments, especially the deaf and hard of hearing while, on the other hand, we were able to notice some relative progress in the reduction of barriers encountered by those with mobility impairments.

Summing up, the most important finding of the two phases is that adopting laws and regulations alone has no meaning if these are not effectively implemented in practice. Both the LivingAll and Slovenian research projects lead to the same crucial conclusion, i.e., something else needs to be done. It was found that in order to be able ever to create a barrier-free environment, there was an urgent need to devise some new ways or mechanisms that would enable greater efficiency in the realization of the rights of people with disabilities to barrier-free access. The development of such a solution was therefore the focus of the last phase of the research. The principle behind this effort was to design a mechanism that would introduce fundamental changes to existing structures of socio-political responsibility and accountability. We believe that the only way to achieve progress in this area is through the adjustment of roles and the reversal of approaches. A bottom-up approach is seen as the core to the development of a solution that would have the capacity to achieve success in the fight to remove barriers. The result of our effort is the interactive web tool that we present below. 


\subsection{The Interactive Web Tool}

The interactive web tool is composed of four main parts:

- Internet (website) guide

- Web forum

- Technical instrument for assessing accessibility

- Monitoring service

\subsubsection{Internet Guide}

The data gathered during the field investigations of public facilities presents the basis for the information that is published on the Internet guide. That means that the internet guide provides information on the accessibility of all the facilities that have been examined with the application of the technical instrument for assessing accessibility. There are two ways of searching information on the Internet guide, i.e., either by filtering places or activities. If browsing by place is chosen, the user clicks the name of the place where the facility or service about which information is sought is located. This opens a window which shows all the facilities, services or activities about which information is available in the guide. The final click on the particular service or activity opens the page(s) on which information is provided on the accessibility of all the facilities providing the specific service the user is interested in (see Figure 1).

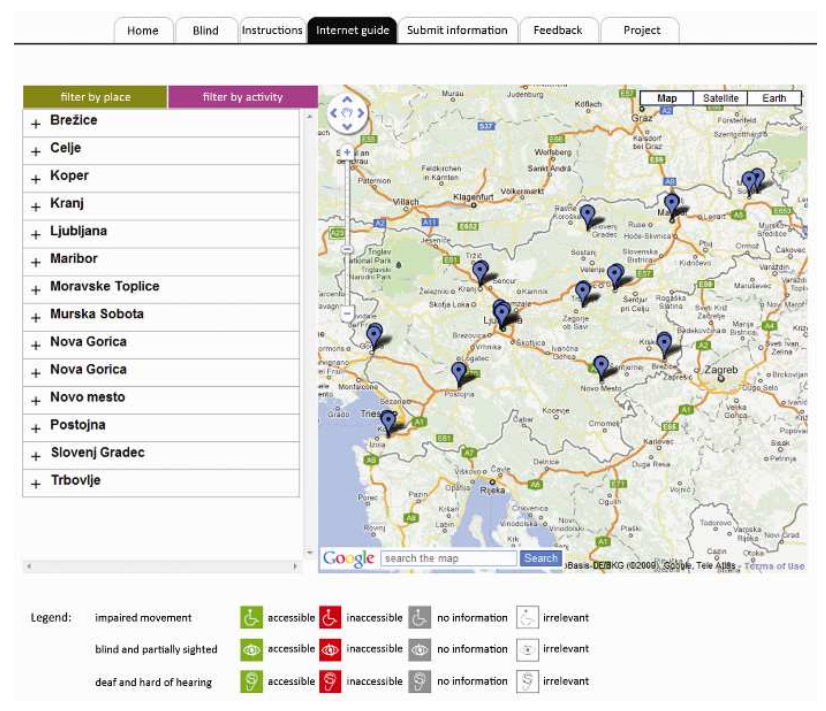

Figure 1: Internet guide for people with disabilities

Alternatively, the user may choose to conduct the search by activity. By clicking, for example on education, a dialogue box will open which will show all the places where information is available on the accessibility of educational facilities. A click on each of these places opens a list of all the educational facilities in a particular area. The final click on a specific facility gives the list with the information on the accessibility of the facility.

Irrespective of the chosen method of search, the information on the accessibility of a particular facility may be further filtered by type of disability which means that the user obtains only the information that relates to the particular disability of interest. The accessibility (or not) of a particular facility for a particular form of disability is shown by the colour of the symbol representing that disability whereby green means accessible, red inaccessible, gray no information and no colour means irrelevant (for example, spaces for people on wheel chairs in theatres are not relevant to other categories of disability). Finally, this information may be printed out if the user chooses to.

It is also important to point out that the internet guide also includes information on the sources (laws, regulations and standards) on which the accessibility assessment criteria are based. This section is, primarily, meant for the owners or managers of facilities who may wish to know why a particular aspect of their facility was marked in the guide as inaccessible. At the same time, this information is also intended to serve as a means of educating or raising awareness of the general public about the various barriers encountered by people with disabilities. As explained below, the general public is also expected to play a role in the processes of the removal of built-environment and communication barriers.

\subsubsection{Web Forum}

Besides the guide the web tool also includes a web forum. This is an interactive portal which was created to enable the active participation of people with disabilities and the general public in the identification of barriers in any place in the country. The web forum offers a means of gathering relevant information with the help of the general public which is invited to provide information about any barriers that they observe in their environment. This approach is intended to result in gradual identification of barriers over the entire Slovenian territory and, hopefully, their eventual elimination. It is also vital to point out that, in addition to the identification of existing barriers, the general public is also requested to report barriers 'in the creation', i.e., those that they observe to be being newly constructed. The purpose of this measure is, of course, to prevent the appearance of new barriers.

The system provides two ways of supplying information. This may be done by entering the required information directly into the window that appears when the user clicks on submit information. The second possibility is by clicking on a particular facility on the map whereby a window opens into which the relevant information is entered. In either case the participant is required to supply the following information: name of place, name/type of facility, address of facility, zip-code, e-mail address of participant and a brief description of the nature of the barrier being reported. The only difference between the two methods is in the recognition, by the designers of the forum, that some participants may not wish to scroll through Google Maps to locate the particular facility they want to address. In addition to reporting barriers, the web forum provides people with disabilities with a medium for mutual exchange of information and experiences. In this sense, it is also intended to serve as a communication social network though which people with disabilities are encouraged to develop new ideas 
and suggest proposals for improvement.

\subsubsection{Technical Instrument for Assessing the Accessibility of Facilities in Public Use}

The interactive web tool is designed in such a way that it also possible to use as a technical instrument for assessing the accessibility of public facilities. This quality emerges from the fact that the inspection list criteria for determining accessibility take into account all relevant legal requirements and current standards. As such, the inspection list accurately verifies conformity with regulations which makes it a suitable instrument for conducting technical inspections of the accessibility of public facilities. As such, the managers of the various public facilities may choose to commission the examination of the accessibility of their facilities with the application of the assessment list. In this sense, the comprehensive inspection list is a precious novelty for the building inspectorate services as it has the capacity to considerably ease their access to information on the (in)accessibility of public facilities. The application of the tool for these purposes does, of course, require the establishment of a special relationship of cooperation between the building inspectorate and the operator of the web tool.

\subsubsection{Service for Monitoring Spatial Developments and Taking Appropriate Action}

The information provided on the web forum is received and processed by the administrator of the interactive tool. This, of course, requires putting in place an appropriate and efficient system for processing and handling the information gathered. For this purpose, a monitoring service has been created whose task is to perform the initial processing of the information obtained. The initial processing stage involves sorting the information into the following four main actions:

- respond to an inquiry or provide requested information;

- alert the owner/manager of the particular facility about the reported barrier;

- take urgent action (notify the competent state control authority, especially in case of new construction under way that blatantly violates current regulations);

- conduct further field investigation.

The information sorted out in this way by the operator of the monitoring service is then passed on to the competent institutions or experts who are required to take appropriate action.

\section{Defining the Interactive Web Tool as a Social Innovation}

We are certain that the development of the interactive web tool presented here is a significant step towards the practical realization of the various commitments that have, for long periods, continued to remain declarations on paper without effective implementation. Furthermore, we also find that the web tool has numerous characteristics that qualify it as a social innovation. Before we proceed to identify these characteristics we, first of all, briefly describe the notion of social innovation as discussed in the literature and, against this background, develop a working framework which we use to establish the innovative nature of the interactive web tool.

A review of the literature on social innovation in the area of urban development shows that the subject has, so far, received limited academic discourse. This situation is described by various authors with phrases such as 'relatively understudied' (Sharra and Nyssens, 2009), 'underinvestigated' (Mumford, 2002), 'research in this area is in its infancy' (Read, 2000), while Howaldt and Schwarz (2010) and Moulaert et al. (2005) recognize a surge of the topic in social science analyses in the western world over the last twenty years. Prior to this period, some writers on the subject (for example Mouelaert et al., 2005; Mumford, 2002; Howaldt and Schwarz, 2010; Hubert, 2010) make reference to the earlier introduction of the social innovation theme at the turn of the nineteenth-century by Max Weber and by Joseph Schumpeter in the early 1990s. This literature deficit was recognized also by the authors of the report of the Workshop on Social Innovation, which was produced under the auspices of the Bureau of European Policy Advisers (BEPA) of the European Commission, who found that the subject was 'insufficiently researched' (Hubert et al., 2010). In view of the absence of an extensive academic debate on the theme, it is generally accepted that there is no established definition of social innovation in the current literature. Read (2000) finds an initial difficulty in innovation research in defining exactly what innovation is. He also warns of the frequent difficulty in establishing a distinction between an innovation and invention. On the other hand, Mumford (2002) suggests methodological complexity as being one of the major considerations that has made it difficult to study social innovation. He argues that it is difficult to identify and attribute a creative act "... when multiple parties are involved and there is no fixed outcome" (ibid.: 254). Read (2000) makes reference to some researchers (for example Abramson, 1991; Eveland, 1991) who have expressed the belief that a general theory of innovation is impossible due to the many complexities involved.

However, it is vital to stress that we are not aiming, in this paper, at analyzing social innovation theory or formulating a comprehensive definition of the phenomenon. Our task here is to demonstrate, according to current scholarly views, that the interactive web tool we developed is a social innovation. It is therefore important to note that despite the stated relative under-theorization of the subject, different authors have identified several characteristics and suggested various definitions of social innovation which provide a useful context within which we discuss and draw support for the argument that the interactive web tool is a social innovation.

Mumford (2002) identifies several characteristics of social innovation, among them, the following:

- "Social innovation refers to the generation and implementation of new ideas about how people should organize personal activities, or social interaction, to 
meet one or more common goals" (ibid.: 253).

- "Social innovation might involve in the creation of new processes and procedures for structuring collaborative work, the introduction of new social practices in a group, or the development of new business practices" (ibid.: 253).

- "Social innovation requires ideas and solutions that are based on identifying a limited number of manageable key issues" (ibid.: 263).

- "Social innovation is, at its core, an inherently practical activity in which benefit must be demonstrated in a relatively short period" (ibid.: 264).

- "Social innovation involves a willingness to rearrange or restructure existing social relationships to address the issue at hand" (ibid.: 264).

The statements quoted above may be condensed to highlight the major characteristics of social innovation, according to Mumford (2002), as: the implementation of new ideas, social interaction, the creation of new processes and restructuring social relations.

Moulaert et al. (2005: 1970) argue that “... the general social rationale of social initiatives is to promote inclusion into different spheres of society (especially the labor market, education system and social-cultural life), while the political rationale is to give a 'voice' to groups that have been traditionally absent from politics and the politico-administrative system at the local and other institutional/spatial scales." They also observe that "...most contemporary discussions about social innovation stress the 'process' dimension of social innovation - i.e. the governance and capacity building (empowerment) dynamics of social movements and initiatives" (ibid.: 1976) and define the following dimensions of social innovation (ibid.: 1976, italics in original text):

- "satisfaction of human needs that are not currently satisfied, either because 'not yet' or because 'no longer' perceived as important by either the market or the state (content/product dimension);

- changes in social relations, especially with regard to governance, that enable the above satisfaction, but also increase the level of participation of all but especially deprived groups of society (process dimension);

- increasing the socio-political capability and access to resources needed to enhance rights to satisfaction of human needs and participation (empowerment dimension)."

- For the purposes of their article, Moulaert et al. (2005: 1978) then formulate the following four-statement working definition of social innovation:

- "Social innovation is path-dependent and contextual. It refers to those changes in agendas, agency and institutions that lead to a better inclusion of excludes groups and individuals in various spheres of society at various spatial scales.

- Social innovation is very strongly a matter of process innovation - i.e. changes in the dynamics of social relations, including power relations.
- As social innovation is very much about social inclusion, it is also about countering or overcoming conservative forces that are eager to strengthen or preserve social exclusion situations.

- Social innovation therefore explicitly refers to an ethical position of social justice. The latter is of course subject to a variety of interpretations and will in practice often be the outcome of social construction."

For Moulaert et al. (2005) social innovation is about promoting inclusion, governance and capacity building, satisfaction of human needs, changing social relations, empowerment, changes in agendas that lead to a better inclusion of excluded groups, and the promotion of social justice.

In the Stanford Social Innovation Review, Phills et al. (2008: 34), define social innovation "the process of inventing, securing support for and implementing novel solutions to a social problem." More precisely, they define social innovation as "a novel solution to a social problem that is more effective, efficient, sustainable, or just than existing solutions and for which the value created accrues primarily to society as a whole rather than private individuals." Social innovation is seen, in this case, as a process that commences with inventing a solution to solve a social problem for the good of society in general.

In a similar manner, Murray et al. (2010: 3) define social innovation as "new ideas (products, services and models) that simultaneously meet social needs and create new social relationships or collaborations. In other words, they are innovations that are both good for society and enhance society's capacity to act." In addition to delivering good for society, this definition also refers to the creation of new social relations and the enhancement of society's role.

Howaldt and Schwarz (2010: 23) quote Kesselring and Leitner's (2008) definition which states that social innovations are elements of social change that “... create new social facts, namely impacting the behavior of individual people or certain social groups in a recognizable way with an orientation towards recognized objects that are not economically motivated." Kesselring and Leitner's definition thus adds a new element to the previous definitions, namely, the non-economic motivation of a social innovation.

One of the most detailed recent studies on the subject was conducted by researchers who participated in the already mentioned BEPA Workshop on Social Innovation (Hubert et al., 2010). Their extensive report provides a thorough examination of the key issues of social innovation in Europe and offers a variety of perspectives on the subject, on the basis of which the authors develop their definition of the term. A selection of some of the characteristic elements of social innovation identified in the study is presented below:

- "The overriding social issue for the longer term is how to equip individuals with the right skills to give them the best chance in the modern economy as workers, entrepreneurs and consumers" (ibid.: 21).

- "Social innovation also mobilizes each citizen to 
become an active part of the innovation process" (ibid: $30)$.

- "Innovation refers to the capacity to create and implement novel ideas which are proven to deliver value. 'Social' refers to the kind of value that innovation is expected to deliver: a value that is less concerned with profit and more with issues such as quality of life, solidarity and well-being ... As it is used now in public and scientific debates, it is about developing innovative solutions and new forms of organization and interactions to tackle social issues" (ibid: 33).

- "In general, social innovation can be defined as a new response to pressing social demands, which affect the process of social interactions. It is aimed at improving human well-being" (ibid: 33).

- "Social innovations are innovations that are social in both their ends and their means. Specifically, we define social innovations as new ideas (products, services and models) that simultaneously meet the social needs (more effectively than alternatives) and create new social relationships or collaborations. In other words, they are innovations that are not only good for society but also enhance society's capacity to act" (ibid: 33 ).

Recognizing that "social innovation, as a new and emerging concept, cannot be encapsulated within a tight definition with strictly designated actors, objectives and means" (ibid: 42) they develop a definition composed of two dimensions:

a) the process dimension, which defines social innovation as "relating to the development of new forms of organization and interactions to respond to social issues" (ibid.: 43), and

b) the outcome dimension which suggests that social innovation aims at addressing:

- "Social demands that are traditionally not addressed by the market or existing institutions and are directed towards vulnerable groups in society.

- Societal challenges in which the boundary between 'social' and 'economic' blurs, and which are directed towards society as a whole.

- The need to reform society in the direction of a more participative arena where empowerment and learning are sources and outcomes of well-being" (ibid: 43, italics in original text).

The key elements of social innovation specified in the BEPA study are, therefore, equipping individuals, mobilizing citizens, creating and implementing novel ideas, responding to pressing social demands, creating new social relationships, addressing vulnerable groups and enhancing society's capacity to act to the benefit of society as a whole. While the process and outcome dimensions suggested in the definition formulated by the authors of the study essentially make reference to characteristics similar to those already presented above, they also introduce two vital elements, i.e., participation and empowerment. Both elements are crucial for ensuring success in the implementation of new solutions.

For still better legibility we present, with the help of keywords, a summary of the characteristic elements of social innovation reviewed above (Figure 2).

\begin{tabular}{|c|c|c|c|}
\hline Mumford (2002) & Moulaert et al. (2005) & $\begin{array}{l}\text { Howaldt and Schwarz } \\
(2010)\end{array}$ & Hubert et al. (2010) \\
\hline $\begin{array}{l}\text {-generation and implementation of new } \\
\text { ideas } \\
\text {-organization of personal activities } \\
\text {-social interaction } \\
\text {-creation of new processes } \\
\text {-structuring collaborative work } \\
\text {-introduction of new social practices } \\
\text {-rearranging or restructuring existing } \\
\text { social relationships } \\
\text {-addressing issues at hand }\end{array}$ & $\begin{array}{l}\text {-promoting inclusion } \\
\text {-giving a voice to marginalized groups } \\
\text {-governance } \\
\text {-capacity building } \\
\text {-satisfaction of human needs } \\
\text {-changes in social relations } \\
\text {-changes in agendas } \\
\text {-inclusion of excluded groups } \\
\text {-increasing socio-political capability } \\
\text {-participation } \\
\text {-empowerment } \\
\text {-social inclusion } \\
\text {-overcoming conservative forces that } \\
\text { preserve social exclusion situations } \\
\text {-social justice }\end{array}$ & $\begin{array}{l}\text {-social change } \\
\text {-creation of new social } \\
\text { facts }\end{array}$ & $\begin{array}{l}\text {-equipping individuals with the right } \\
\text { skills } \\
\text {-mobilization of citizens } \\
\text {-creation and implementation of } \\
\text { novel ideas } \\
\text {-responding to pressing social } \\
\text { demands } \\
\text {-improving human well-being } \\
\text {-creation of new social relationships } \\
\text { and collaborations } \\
\text {-enhancing society's capacity to act } \\
\text {-social interaction between } \\
\text { individuals }\end{array}$ \\
\hline
\end{tabular}

Figure 2: Characteristic elements of social innovation (developed by author)

While different authors use different expressions to describe the social innovation phenomenon, it is possible to discern from Table 1 several elements that may be argued to be common to the thinking of the authors reviewed. We may, therefore, further condense the summarized keywords to identify four basic general characteristics that define a social innovation. These are:
- Initiation

- Creation of new ideas

- Mobilization of citizens

- Achieving change

In continuation, we apply these characteristics to argue and demonstrate that the interactive web tool we created is a social innovation. For this purpose, we have designed what 
we have termed the social innovation chain, a useful framework that enables us to clearly identify the elements of the interactive web tool that characterize it as a social innovation. These relationships are schematically illustrated in Figure 3.
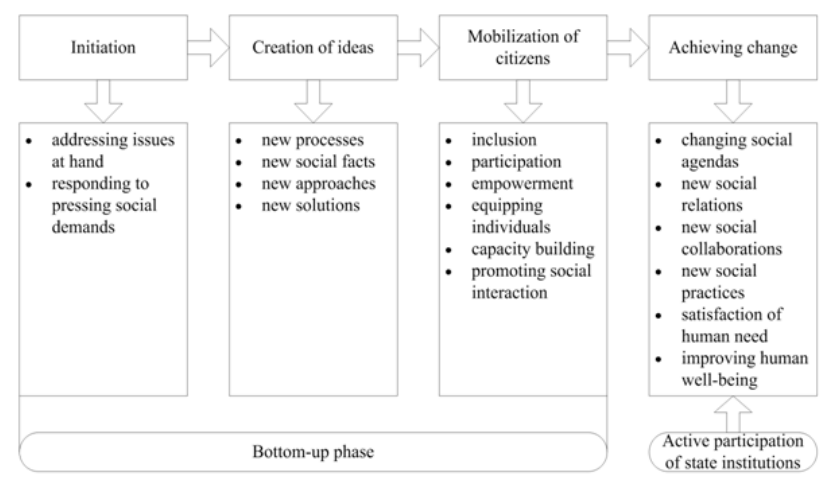

Figure 3: Social innovation chain

The review of the literature has thus shown that social innovation is a process that is executed through a sequence of events. We describe this process, hence forth, as the social innovation chain. The social innovation chain begins (initiation) with the recognition of the presence of a social problem that needs to be addressed. The development of our interactive web tool was initiated by the findings of the two research projects referred to in the introduction to the paper, i.e., the European-wide EU funded LivingAll project and the more focused Slovenian research. As was stated in the introduction, the results of both researches showed that little progress has been achieved, this far, in the realization of the rights of people with disabilities to barrier-free access. The initiation of the innovation was, thus, triggered off by the continued existence of a social problem, in spite of the numerous international resolutions, declarations and directives (at the EU level) and national legislation and action programs, that have been adopted over the last decades, intended to guarantee free access for all. In other words, the process of designing the interactive web tool was initiated in response to a pressing social need. It is important to stress here that addressing a social problem requires a thorough understanding of its nature, its cause(s), and the reasons why previous solutions (if any) have not been successful. A lack of this essential knowledge may pose a danger of suggesting solutions that may, once again, turn out to be inappropriate and, therefore, fail to achieve the desired goals. The two research projects conducted on the subject equipped us with the background knowledge necessary to proceed to the next step of the social innovation chain.

Once the background knowledge was obtained, the next step of the process was to search for new ideas that would lead to the introduction of a more efficient solution to the problem at hand. This stage involved the mobilization of resources or, as we have already quoted Mumford (2002), the organization of personal activities. We have also quoted Moulaert et al. (2005: 1972) who stated that "the more grassroots, spontaneous, creative initiatives, those which develop against or seek to change established practices from below, are also the most innovative." It was therefore imperative that we focused the search for new ideas on the social groups affected by the issues being addressed, i.e., on those who would mostly benefit from the social innovation. Concretely, this required the active involvement of people with disabilities in the development of solutions and efficient mechanisms for their implementation. The role played by people with disabilities persons that physically participated in the field investigation of existing built-environment and communication barriers was precious. Besides helping us to discover more accurately the various barriers they encounter (some of which we might have missed, had we performed the investigations without them), they also contributed greatly to the process, with their spontaneous suggestions and ideas on how to effectively remove specific barriers.

The importance of citizen participation in the creation of new ideas for a social innovation was also referred to by Hubert et al. (2010) as one of the recommendations of EQUAL (Community initiative within the European Social Fund of the EU, which ran from 2001 till 2007) where it was underlined that "Solutions must focus on the beneficiaries and be created with them, preferably by them, and never without them." (Hubert et al. 2010: 35). This requirement ties in appropriately with the next stage of the social innovation chain, i.e., the mobilization of citizens. This is the stage during which the participation of citizens in the implementation of new ideas and solutions is facilitated. The web forum of our interactive web tool provides an efficient medium for the mobilization of citizens. It is vital to stress that the tool is not intended solely for the use of people with disabilities. All citizens are invited to actively participate in the identification of existing barriers and the prevention of the appearance of new ones. Everybody (people with disabilities and others) will be able to contribute information on discovered barriers and will also be offered the opportunity to forward, through the forum, suggestions for improvement. As has been established by the literature review, the mobilization of citizens is a measure that is essential for the development of new forms of social relations and promoting social interaction. We have also quoted Hubert et al. (2010) who find that innovations that are implemented through the inclusion, participation and empowerment of citizens are not only good for society but also enhance society's capacity to act. In this regard, the tool is also expected to make a major contribution to raising general awareness about the problems encountered by the disabled, due to the barriers created by those without disabilities. This lack of awareness was one of the major problems stated by the respondents who participated in the two referenced research projects.

The citizen mobilization dimension of the social innovation chain is crucial as it helps to impact the behaviour of individuals or certain groups. As we have quoted Moulaert et al. (2005: 1978), this approach contributes to the "overcoming of conservative forces that 
are eager to strengthen or preserve social exclusion situations". The literature review has also indicated that social innovation processes that prioritize citizen participation and promote social interaction are likely to lead to solutions that are more effective and more sustainable. Social interactions between various stakeholders are, therefore, vital for ensuring the realization of the set objectives, i.e. achieving change for the better. Achieving change has been described in the literature as encompassing; changing social agendas, restructuring existing relationships, creating new social relations, creating new collaborations and new practices, the satisfaction of human needs and improving human well-being. The interactive web tool includes measures that effectively impact on and require the introduction of changes to current social agendas. The tool advances the current political (lip service) rhetoric on barrier-free access to a higher level where the removal of built-environment and communication barriers becomes a more realizable goal than it has been in the past. The interactive web tool certainly presents an effective solution to the problem that we set out to solve. Its practical implementation will result in satisfying an important human need and, consequently, in improving the well-being of people with disabilities.

Following this presentation, the argument for defining the interactive web tool as a social innovation can be concluded by quoting, once again, Hubert et al. (2010: 33), who defined the phenomenon as “... new ideas (products, services and models) that simultaneously meet the social needs (more effectively than alternatives) and create new social relationships or collaborations. In other words, they are innovations that are not only good for society but also enhance society's capacity to act." The interactive web tool is a product, service and model that satisfies all elements of this definition.

\section{Conclusion}

As was pointed out in the introduction to the paper, the rights of people with disabilities to barrier-free access and equal opportunities are guaranteed by numerous documents at the international and national levels. Laws and regulations have been adopted providing for the elimination of all forms of discrimination and the removal of various barriers and other restrictions in the environment. Legislation also prescribes the need for the provision of the support necessary for enabling people with disabilities independent living. However, the results of our researches showed that little has been done to transfer these noble objectives from paper to practice. It was found that persons with disabilities are still not able to fully participate in society. The more focused Slovenian research confirmed that barriers continue to exist (and be created) in the built environment as well as in communication means.

These research findings strongly motivated our search for new solutions that would make easier the realization of the rights of people with disabilities to barrier-free access. The interactive web tool presented above is the mechanism that enables us to make the giant leap from paper declarations to real action. With its four constitutive parts, the tool presents a comprehensive instrument which, to our knowledge, is the first of its kind among current approaches to tackling built-environment and communication barriers. While the internet web guide for people with disabilities is, certainly, a widely established information medium, we are confident to suggest that the interactive web tool presented here, with all its constituent parts, is a novelty in this area. More concretely, it is a bottom-up social innovation, in stark contrast to current top-down approaches. As a bottom-up solution, the interactive web tool's major characteristic and advantage is its capacity to mobilize citizens to act. Actions in this area that do not actively engage both people with disabilities and the general public have little chance of succeeding. In this respect the interactive web tool provides a new and more efficient mechanism in the fight to remove (and hopefully eventually eliminate) the various barriers that inhibit people with disabilities from fully participating in society, contributing to general economic development and improving their own well-being.

In addition to the operations described in the presentation, the interactive web tool will, in the future, expand its services also to include proving additional information such as, working hours of key public offices and information on contact persons responsible for specific matters, important for people with disabilities. A service will also be provided for explaining various technical issues and elaborating complicated legal matters concerning the rights and various situations of the disabled.

Furthermore, the interactive web tool also has another important characteristic, namely, the potential for transferability. As has been argued above, the web forum, technical instrument and monitoring service are new solutions that have the capacity to be replicated in other countries subject to specific adjustments. The most complex instrument to adapt would be the inspection list which requires a preliminary review of all regulations concerning barrier-free access in a particular country. The inspection list is, of course, the principle instrument for assessing the accessibility of facilities. As such, it must be prepared with utmost sensitivity and accuracy, to ensure that all the vital requirements stipulated by the regulations and standards are covered.

The next major challenge is, of course, the successful implementation of the social innovation. Mumford (2002: 263 ) has rightly cautioned: "Not only does social innovation apparently call for some unique skills and expertise, it also makes some unique demands with regard to solution implementation." It is important to stress, here, that the implementation of the interactive web tool requires also the active participation of various state institutions (ministries, bodies and other organizations) competent in the area of care for the disabled. The specific government departments are responsible for providing the necessary basic support for the practical operation of the interactive web tool as well as 
ensuring that the relevant planning and building regulations are fully conformed with. The role, especially, of the building inspectorate in imposing prescribed sanctions against violations is vital. The experts conducting field inspections and monitoring spatial developments have no powers (legal or otherwise) to enforce the execution of recommended actions. Cooperation between the experts and the competent inspectorate services is thus urgent. In this respect, the interactive web tool also presents an additional advantage, i.e., it simplifies the building inspectorate's work, increasing its efficiency in ensuring compliance with regulations. The active role of all competent state institutions is the final act of the social innovation chain. If everyone plays their role, the implementation of the interactive web tool will leave us with no more excuses for failing to act to achieve change and improve the well-being of the disabled.

\section{Acknowledgment}

We are grateful to the Slovenian Research Agency and the Ministry of Labour, Family and Social Affairs who financially supported the research project which resulted in the creation of the interactive web tool presented in this paper. We are also thankful to The Disabled Students Association of Slovenia, especially its members, who participated in the field investigation.

\section{References}

[1] Balchin P, Rhoden M 1998, Housing: the essential foundations. (Routledge, London)

[2] Barlow J, Venables T, 2004, "Will technological innovation create the true lifetime home?" Housing Studies 19(5) $795-810$

[3] Barnes C, 2011, "Understanding disability and the importance of design for all" Journal of Accessibility and Design for All, 1(1) 55-80

[4] Botchwey N D, Hobson S E, Dannenberg A L, Mumford K G, Contant C K, McMillan T E, Jackson R J, Lopez R et al., 2009, "A model curriculum for a course on the built environment and public health: training for an interdisciplinary workforce" American Journal of Preventive Medicine, 36(2) (supplement) S63-S71.

[5] Brenton M, 2001, "Older people's cohousing communities", in Inclusive housing in an ageing society. Innovative approaches Eds M S Peace, C Holland (Policy Press, Bristol) pp 169-188

[6] Brewerton J Darton D, 1997, Designing lifetime homes (Joseph Rowntree Foundation, York)

[7] Bulos M, Teymur N, 1993, Housing: design, research, education (Avebury, Aldershot)

[8] Burns N, 2004, "Negotiating difference: disabled people's experiences of house builders" Housing Studies 19(5) $765-780$
[9] Chan E H W, Lee K L G, Chan A T S, 2009, "Universal design for people with disabilities: a study of access provisions in public housing estates" Property Management 27(2) 138-146.

[10] Coleman R, 1997 Working together: a new approach to design (Royal College of Art, London)

[11] Dewsbury G, Rouncefield M, Clarke K, Sommerville I, 2004, "Depending on digital design: extending inclusivity" Housing Studies 19(5) 811-25

[12] EC, 1997, "Treaty of Amsterdam" Official Journal C 340/1997, 2 October 5-181 (European Commission, Luxembourg)

[13] EC, 2003, "Equal Opportunities for people with disabilities: a European action plan. COM (2003) 650 final" (European Commission, Brussels)

[14] EC, 2000, "Council Directive 2000/43/EC of 29 June 2000 implementing the principle of equal treatment between persons irrespective of racial or ethnic origin" Official Journal of the European Communities, L 180 22-26, 29 June (European Commission, Luxembourg)

[15] EC, 2010, "European disability strategy 2010-2020: a renewed commitment to a barrier-free Europe. $\operatorname{COM}(2010)$ 636 final" (European Commission, Brussels)

[16] Ellison N, Burrows R, 2007, "New spaces of (dis)engagement? Social politics, urban technologies and the rezoning of the city" Housing Studies 22(3) 295-312

[17] Fisk M J, 2001, "The implication of smart home technologies", in Inclusive housing in an ageing society. Innovative approaches Eds M S Peace, C Holland (Policy Press, Bristol) pp 101-124

[18] Garcés J, Sendi R, Černič Mali B, Kerbler B, Kobal Tomc B, 2007, "Free movements and equal opportunities for all (LivingAll). Compilation and classification of the national policies and action plans in Europe (LivingAll national initiatives report)", Polibienestar, Valencia

[19] Goodall B, Pottinger K G, 2010, "Promoting inclusive access to the built environment", CEM Occasional Paper, College of Estate Management, Reading

[20] Gore E, Parckar G, 2010, Rights and reality: disabled people's experiences of accessing goods and services (Leonard Cheshire Disability, London)

[21] Gossett A, Mizra, M, Barnds A K, Feidt D, 2009, "Beyond access: a case study on the intersection between, accessibility, sustainability and universal design" Disability and Rehabilitation: Assistive Technology 4(6) 439-450.

[22] Hanson J, 2001, From special needs to lifestyle choices, in Inclusive housing in an ageing society. Innovative approaches Eds M S Peace, C Holland (Policy Press, Bristol) pp 29-52

[23] Hanson, J, (2004) "The inclusive city: delivering a more accessible urban environment through inclusive design", in Proceedings of the RICS Foundation Construction and Building Research Conference - COBRA 2002, 5-6 September 2002 Ed R Morledge (Trent University, Nottingham) pp 1-39

[24] Harris J, 2010 "The use, role and application of advanced 
technology in the lives of disabled people in the UK" Disability \& Society 25(4) 427-439

[25] Harrison M, 2004, "Defining housing quality and environment: disability, standards and social factors" Housing Studies 19(5) 691-708

[26] Harrison M, Davis C, 2001, Housing, social policy and difference: disability, ethnicity, gender and housing (Policy Press, Bristol)

[27] Hemingway L, 2011, Disabled people and housing: choices, opportunities and barriers (Policy Press, Bristol)

[28] Heywood F, 2004, "Understanding needs: a starting point for quality” Housing Studies 19(5) 709-26.

[29] Howaldt J, Schwarz M, 2010, Social innovation: concepts, research fields and international trend (Sozialforschungsstelle Dortmund \& ZWE der TU-Dortmund, Dortmund)

[30] Hubert A 2010 Empowering people, driving change: social innovation in the European Union (European Commission, Brussels)

[31] Hutch D J, Bouye E K, Skillen E, Lee C, Whitehead L T, Rashid J R, 2011, "Potential strategies to eliminate built environment disparities for disadvantaged and vulnerable communities" American Journal of Public Health 101(4) 587-95.

[32] Imrie R, 2011, "Universalism, universal design and equitable access to the built environment" Disability and Rehabilitation 34, 1-10.

[33] Imrie R, 2000, "Responding to the design needs of disabled people" Journal of Urban Design 5(2) 199-219

[34] Imrie R, 2004a, "Disability, embodiment and the meaning of home" Housing Studies 19(5) 745-763

[35] Imrie R, 2004b, "Housing quality, disability and domesticity" Housing Studies 19(5) 685-690.

[36] Kelly M, 2001, Lifetime homes, in Inclusive housing in an ageing society. Innovative approaches Eds M S Peace, C Holland (Policy Press, Bristol) pp 55-75

[37] Lombardi A R, Murray C, 2011, "Measuring university faculty attitudes toward disability: willingness to accommodate and adopt universal design principles" Journal of Vocational Rehabilitation 34(1) 43-56

[38] Mace R, 1998, "Universal design in housing" Assistive Technology 10(1) 21-28.

[39] McGrail B, Percivel J, Foster K, 2001, Integrated segregation? in Inclusive housing in an ageing society. Innovative approaches Eds M S Peace, C Holland (Policy Press, Bristol) pp 147-168

[40] Milner J, Madigan R, 2004, "Regulation and innovation: rethinking inclusive housing design" Housing Studies 19(5) 727-744.

[41] Moulaert F, Martinelli F, Swyngedouw E, Gonzalez S, 2005,
"Towards alternative model(s) of local innovation" Housing Studies 42(11) 1969-1990.

[42] Mumford M D, 2002, "Social innovation: ten cases from Benjamin Franklin" Creativity Research Journal 14(2) 253-266

[43] Murray R, Caulier-Grice J, Mulgan G, 2010, The open book of social innovation (The Young Foundation and Nesta, London)

[44] Peace M S, Holland C, 2001, Inclusive housing in an ageing society. Innovative approaches. (Policy Press, Bristol)

[45] Pecora F, Cesta A, 2007, DCOP for smart homes: a case study. Computational Inelligence 23(4) 395-419

[46] Phills J A, Deigmeir K, Miller D T 2008, "Rediscovering social innovation" Stanford Social Innovation Review 6(4) $34-43$.

[47] Pillan M, Fiammetta C, 2009, "User-centerd design of communication environments and systems for disabled people" Knowledge, Technology \& Policy 22(4) 265-273

[48] Prideaux S, 2006, Good practice for providing reasonable access to the physical built environment for disabled people (The Disability Press, Leeds)

[49] Prideaux S, Roulstone A, 2009, "Good practice for providing disabled people with reasonable access to the built environment: a comparative study of legislative provision" International Journal of Law in the Built Environment 1(1) $59-81$

[50] Read A, 2000, "Determinants of successful organizational innovation: A review of current research" Journal of Management Practice 3(1) 95-119

[51] Sandhu J S, Saarnio I, Wiman R, 2001, Information and communication technologies and disability in developing counties (World Bank, Washington)

[52] Sendi R, Bizjak I, Kerbler B, Tominc B, Goršič N, Nikšič M, Mujkić S, Kobal Tomc B, et al., 2011, "Ukrepi za uresničevanje pravic invalidov do dostopa brez ovir: inventarizacija obstoječih ovir $\mathrm{v}$ grajenem okolju in $\mathrm{v}$ objektih v javni rabi po Sloveniji”, Urban Planning Institute of the Republic of Slovenia, Ljubljana

[53] Sharra R, Nyssens M, 2009, "Social innovation: an interdisciplinary and critical review of the concept" Université Catholique de Louvain, Louvain-la-Neuve, http://www.ces.ulg.ac.be/uploads/Workshop\%203-4\%20Mar ch/Sharra\%20and\%20Nyssens\%202010.pdf

[54] Sherman S, Sherman J, 2012, "Design professionals and the built environment: encountering boundaries 20 years after the Americans with Disabilities Act" Disability \& Society 27(1) $51-64$.

[55] Thomas P, 2004 "The experience of disabled people as customers in the owner occupation market" Housing Studies 19(5) 781-94.

[56] World Health Organization, WHO, Geneva, 2011, "World report on disability" 